\title{
Involvement of stress-activated protein kinase/c-Jun N-terminal kinase in endothelin-1-induced heat shock protein 27 in osteoblasts
}

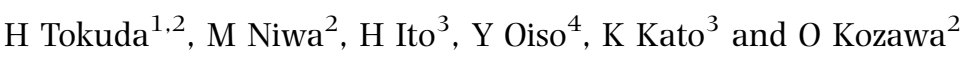 \\ ${ }^{1}$ Department of Internal Medicine, Chubu National Hospital, National Institute for Longevity Sciences, Obu, Aichi 474-8511, Japan, \\ ${ }^{2}$ Department of Pharmacology, Gifu University School of Medicine, Gifu 500-8705, Japan, ${ }^{3}$ Department of Biochemistry, \\ Institute for Developmental Research, Aichi Human Service Center, Kasugai, Aichi 480-0391, Japan and ${ }^{4}$ First Department of Internal Medicine, \\ Nagoya University School of Medicine, Nagoya 466-8550, Japan \\ (Correspondence should be addressed to O Kozawa; Email: okozawa@cc.gifu-u.ac.jp)
}

\begin{abstract}
Objective: We have reported that endothelin-1 (ET-1) activates p38 mitogen-activated protein (MAP) kinase through protein kinase $\mathrm{C}$ in osteoblast-like MC3T3-E1 cells, and that p38 MAP kinase plays a role in the ET-1-induced heat shock protein 27 (HSP27). Recently, we found that stress-activated protein kinase/c-Jun N-terminal kinase (SAPK/JNK) is activated by ET-1 in these cells. In the present study, we have investigated the involvement of SAPK/JNK in ET-1-induced HSP27 in MC3T3-E1 cells. Methods: The concentration of HSP27 in soluble extracts of the cells, the expression of mRNA for HSP2 7, and the phosphorylation of SAPK/JNK were determined by an enzyme immunoassay, Northern blot analysis, and Western blot analysis respectively.

Results: SP600125, a specific inhibitor of SAPK/JNK, markedly reduced ET-1-stimulated HSP27 accumulation. The inhibitory effect of SP600125 was dose dependent in the range between 1 and $50 \mu$ M. SP600125 reduced the ET-1-increased level of HSP27 mRNA. Calphostin C and Go 6976, inhibitors of protein kinase C, reduced the ET-1-induced phosphorylation of SAPK/JNK. 12-O-Tetradecanoylphorbol-13-acetate, a direct activator of protein kinase C, induced SAPK/JNK phosphorylation, which was suppressed by SP600125. A combination of SP600125 and p38 MAP kinase inhibitor such as SB203580 and PD169316 additively reduced the ET-1-stimulated accumulation of HSP27.

Conclusions: These results strongly suggest that JNK plays a part in ET-1-induced HSP2 7 in addition to p38 MAP kinase in osteoblasts.
\end{abstract}

European Journal of Endocrinology 149 239-245

\section{Introduction}

Cells produce heat shock proteins (HSPs) when exposed to biological stress, such as heat stress (1). HSPs are classified into high and low molecular weight HSPs based on their apparent molecular size. It is well known that high molecular weight HSPs, such as HSP90 and HSP70, act as molecular chaperones in protein folding, oligomerization and translocation (1). Low molecular weight HSPs with molecular masses from 10 to $30 \mathrm{kDa}$, such as HSP27, have high homology in amino acid sequences (1). It is currently recognized that low molecular weight HSPs may have chaperoning functions like high molecular weight HSPs (1). Bone metabolism is regulated by two functional cells, osteoblasts and osteoclasts, responsible for bone formation and bone resorption respectively (2). The formation of bone structures and bone remodeling results from coupling bone resorption by activated osteoblasts with subsequent deposition of new matrix by osteoblasts. Accumulating evidence indicates that osteoblasts are responsible for bone-resorptive factors such as parathyroid hormone and $1,25-(\mathrm{OH})_{2}$ vitamin $\mathrm{D}_{3}$ (2) through the up-regulation of receptor activation of NF- $\mathrm{kB}$ ligand (RANKL) expression (3), suggesting that osteoblasts play pivotal roles in the regulation of bone remodeling. In osteoblasts, the expression of HSP27 is induced by heat, which is reportedly facilitated by estrogen $(4,5)$. In addition, it has been shown that the down-regulation of proliferation is accompanied by a transient increase of the expression of HSP 27 mRNA $(4,5)$. We have shown that physiological agents for bone metabolism, such as prostaglan$\operatorname{din} \mathrm{E}_{2}$ and transforming growth factor $\beta$, stimulate the induction of HSP27 in osteoblast-like MC3T3-E1 cells $(6,7)$. However, the exact mechanisms behind the HSP27 induction in osteoblasts and its roles have not yet been precisely clarified. 
Endothelin (ET)-1 is a potent vasoconstrictive peptide that is produced and secreted by endothelial cells $(8,9)$. It is currently recognized that ET has a wide variety of effects on ubiquitous tissues including skeletal tissues through binding to specific receptors (9). During bone remodeling, capillary endothelial cells provide the microvasculature, and osteoblasts and osteoprogenitor cells, which locally proliferate and differentiate into osteoblasts, migrate into the resorption lacuna. Thus, it is currently recognized that the activities of osteoblasts, osteoclasts, and capillary endothelial cells are closely co-ordinated via humoral factors as well as by direct cell-to-cell contact, and these cells co-operatively regulate bone metabolism (10). ET receptors have been shown to exist on osteoblasts (11). It has been reported that ET-1 stimulates bone resorption and decreases alkaline phosphatase activity in vitro, induces collagen and non-collagen protein synthesis in neonatal mouse calvaria, and stimulates the proliferation of osteoblasts (11). Regarding the intracellular signaling system of ET in osteoblasts, it has been reported that ET-1 stimulates $\mathrm{Ca}^{2+}$ mobilization, and phosphoinositide hydrolysis by phospholipase (PL) C (11). We have shown that ET-1 stimulates phosphatidylcholine hydrolysis by PLD in osteoblast-like MC3T3-E1 cells (12). In addition, we have reported that ET-1 activates both p44/p42 mitogen-activated protein (MAP) kinase and p38 MAP kinase in these cells, and that p38 MAP kinase, but not p44/p42 MAP kinase, plays a role in ET-1-stimulated HSP27 induction $(13,14)$. Recently, we demonstrated that ET-1 activates stress-activated protein kinase/c-Jun N-terminal kinase (SAPK/JNK), another member of the MAP kinase family (15). However, the involvement of SAPK/JNK in osteoblast cell function has not yet been precisely clarified.

In the present study, we investigated the involvement of SAPK/JNK in the ET-1-stimulated HSP27 induction in osteoblast-like MC3T3-E1 cells. We here show that SAPK/JNK, in addition to p38 MAP kinase, acts as a positive regulator in ET-1-induced HSP27 in these cells.

\section{Materials and methods}

\section{Materials}

ET-1 was purchased from Peptide Institute, Inc. (Minoh, Japan). SP600125, Go 6976, SB203580 and PD169316 were obtained from Calbiochem-Novabiochem Co. (La Jolla, CA, USA). Calphostin C was obtained from Funakoshi (Tokyo, Japan). 12-O-Tetradecanoylphorbol-13-acetate (TPA) was from Sigma (St Louis, MO, USA), and HSP27 antibodies from Hy Test (Turk, Finland). Phospho-specific SAPK/JNK antibodies and SAPK/JNK antibodies were obtained from New England BioLabs (Beverly, MA, USA). The ECL Western blotting detection system was from Amersham Japan (Tokyo, Japan). Other materials and chemicals were from commercial sources. SP600125, calphostin C,
Go 6976, TPA, SB203580, and PD169316 were dissolved in dimethyl sulfoxide. The maximum concentration of dimethyl sulfoxide was $0.1 \%$, which did not affect the assay for HSP27, Northern blot analysis or Western blot analysis.

\section{Cell culture}

Cloned osteoblast-like MC3T3-E1 cells which were derived from newborn mouse calvaria (16) were maintained as previously described (17). Briefly, cells were cultured in $\alpha$-minimum essential medium $(\alpha$-MEM) containing $10 \%$ fetal calf serum (FCS) at $37^{\circ} \mathrm{C}$ in a humidified atmosphere of $5 \% \mathrm{CO}_{2} / 95 \%$ air. Cells were then seeded into $35 \mathrm{~mm}$ diameter dishes $\left(5 \times 10^{4} / \mathrm{dish}\right)$ or $90 \mathrm{~mm}$ diameter dishes $\left(5 \times 10^{5} /\right.$ dish $)$ in $\alpha$-MEM containing $10 \%$ FCS. After 5 days, the medium was exchanged for $\alpha$-MEM containing $0.3 \%$ FCS. After $48 \mathrm{~h}$, cells were used for experiments.

\section{Immunoassay of HSP27}

The concentration of HSP27 in soluble extracts of the cells was determined by means of a sandwich-type enzyme immunoassay, as described previously (18). The source of HSP27 standard was rat hindlimb muscle, and the HSP27 antibodies showed similar affinity to both phosphorylated and unphosphorylated forms of HSP27 (18). Cultured cells were stimulated by ET-1 for the indicated periods in $1 \mathrm{ml}$ serum-free $\alpha$-MEM. Cells were then washed twice with $1 \mathrm{ml}$ phosphate-buffered saline and frozen at $-80{ }^{\circ} \mathrm{C}$ for a few days before analysis. Frozen cells on each dish were collected and suspended in $0.3 \mathrm{ml}$ phosphate-buffered saline, and then each suspension was sonicated and centrifuged at $125000 \boldsymbol{g}$ for $20 \mathrm{~min}$ at $4^{\circ} \mathrm{C}$. The supernatant was used for an immunoassay employing polystyrene balls $(3.2 \mathrm{~mm}$ in diameter; Immuno Chemicals, Okayama, Japan) carrying immobilized $\mathrm{F}\left(\mathrm{ab}^{\prime}\right)_{2}$ fragments of antibody and the same $\mathrm{Fab}^{\prime}$ fragments labeled with $\beta$-D-galactosidase from Escherichia coli. A polystyrene ball carrying antibodies was incubated either with the purified standard for HSP27 or with an aliquot of the samples. Incubation was carried out at $30^{\circ} \mathrm{C}$ for $5 \mathrm{~h}$ in a final volume of $0.5 \mathrm{ml} 10 \mathrm{~mol} / \mathrm{l}$ sodium phosphate buffer, $\mathrm{pH}$ 7.0, containing $0.3 \mathrm{mmol} / \mathrm{l} \mathrm{NaCl}, 0.5 \%$ hydrolyzed gelatin, $0.1 \%$ bovine serum albumin (BSA), $1 \mathrm{mmol} / \mathrm{l} \mathrm{MgCl}_{2}$, and $0.1 \% \mathrm{NaN}_{3}$. After being washed, each ball was incubated at $4{ }^{\circ} \mathrm{C}$ overnight with $1.5 \mathrm{mU}$ galactosidase-labeled antibodies in a volume of $0.2 \mathrm{ml}$ with $10 \mathrm{mmol} / \mathrm{l}$ sodium phosphate buffer, $\mathrm{pH}$ 7.0, containing $0.1 \mathrm{~mol} / \mathrm{l} \mathrm{NaCl}, 1 \mathrm{mmol} / \mathrm{l} \quad \mathrm{MgCl}_{2}, \quad 0.1 \%$ BSA, and $0.1 \% \mathrm{NaN}_{3}$. The galactosidase activity bound to the ball was assayed using a fluorogenic substrate, 4-methylumbelliferyl- $\beta$-D-galactoside. 


\section{Isolation of RNA and Northern blotting analysis of HSP27}

Cultured cells were stimulated by ET-1 in serum-free $\alpha$-MEM for the indicated periods. Total RNA was isolated using a QuickPrep Total RNA Extraction kit (Pharmacia Biotech, Tokyo, Japan). Next, $20 \mu \mathrm{g}$ total RNA were subjected to electrophoresis on a $0.9 \%$ agarose $-2.2 \mathrm{~mol} / \mathrm{l}$ formaldehyde gel and blotted onto a nitrocellulose membrane. For the Northern blot analysis, the membrane was allowed to hybridize with a cDNA probe that had been labeled with a Multiprime DNA labeling system (Amersham International plc, Amersham, Bucks, UK), as described previously (19). A BamHI-Hind III fragment of cDNA for mouse HSP27 (18) was kindly provided by Dr L F Cooper of the University of North Carolina.

\section{Western blot analysis of HSP27 and SAPK/JNK}

Cultured cells were stimulated by ET-1 or TPA in serum-free $\alpha$-MEM for the indicated periods. Cells were washed twice with phosphate-buffered saline and then lysed, homogenized, and sonicated in a lysis buffer containing $62.5 \mathrm{mmol} / \mathrm{l}$ Tris/Cl, $\mathrm{pH} 6.8,2 \%$ SDS, $50 \mathrm{mmol} / \mathrm{l}$ dithiothreitol, and $10 \%$ glycerol. The cytosolic fraction was collected as a supernatant after centrifugation at $125000 \boldsymbol{g}$ for $10 \mathrm{~min}$ at $4{ }^{\circ} \mathrm{C}$. SDSPAGE was performed by the method of Laemmli (20) in $10 \%$ polyacrylamide gels. Western blotting was performed as described previously (19) using HSP27 antibodies, phospho-specific SAPK/JNK antibodies, or SAPK/JNK antibodies, with peroxidase-labeled antibodies raised in a goat against rabbit IgG used as second antibodies. Peroxidase activity on the nitrocellulose sheet was visualized on X-ray film by an ECL Western blotting detection system (Amersham Japan, Tokyo, Japan). When indicated, cells were pretreated with calphostin C, Go 6976, or SP600125 for $60 \mathrm{~min}$.

\section{Determination}

The absorbance of enzyme immunoassay samples was measured at $450 \mathrm{~nm}$ with an EL 340 Bio Kinetic Reader (Bio-Tek Instruments, Inc., Winooski, VT, USA). Densitometric analysis was performed using Molecular Analyst/Macintosh (Bio-Rad Laboratories, Hercules, CA, USA).

\section{Statistical analysis}

Data were analyzed by ANOVA followed by the Bonferroni method for multiple comparison between pairs, and a difference of $P<0.05$ was considered significant. All data are presented as the means \pm S.E.M. of triplicate determinations. Each experiment was repeated three times with similar results.

\section{Results}

\section{Effect of SP600125 on ET-1-stimulated HSP27 accumulation in MC3T3-E1 cells}

We previously reported that ET-1 activates SAPK/JNK in osteoblast-like MC3T3-E1 cells (15). To investigate whether SAPK/JNK is involved in the ET-1-stimulated HSP27 induction in these cells, we examined the effect of SP600125, a highly specific inhibitor of SAPK/JNK (21), on the accumulation of HSP27. SP600125, which alone did not affect the HSP27 accumulation, significantly suppressed ET-1-stimulated HSP27 accumulation (Fig. 1). The inhibitory effect of SP600125 on ET-1-stimulated HSP27 accumulation was dose dependent in the range between 1 and $10 \mu \mathrm{mol} / \mathrm{l}$ (Fig. 2). The maximum effect of SP600125 on HSP27 accumulation was observed at $10 \mu \mathrm{mol} / \mathrm{l}$, which caused about an $80 \%$ reduction in the ET-1 effect. We previously reported that ET-1 increased the levels of HSP27 with a Western blot analysis using the antibodies for HSP27 utilized in the immunoassay (14). We confirmed that the ET-1-increased HSP27 levels were similarly detectable using the commercially obtained antibodies for HSP27 (Fig. 3).

\section{SP600125 effect on ET-1-increased HSP27 MRNA level in MC3T3-E1 cells}

We next examined the effect of SP600125 on the ET-1increased level of mRNA for HSP27 in MC3T3-E1 cells.

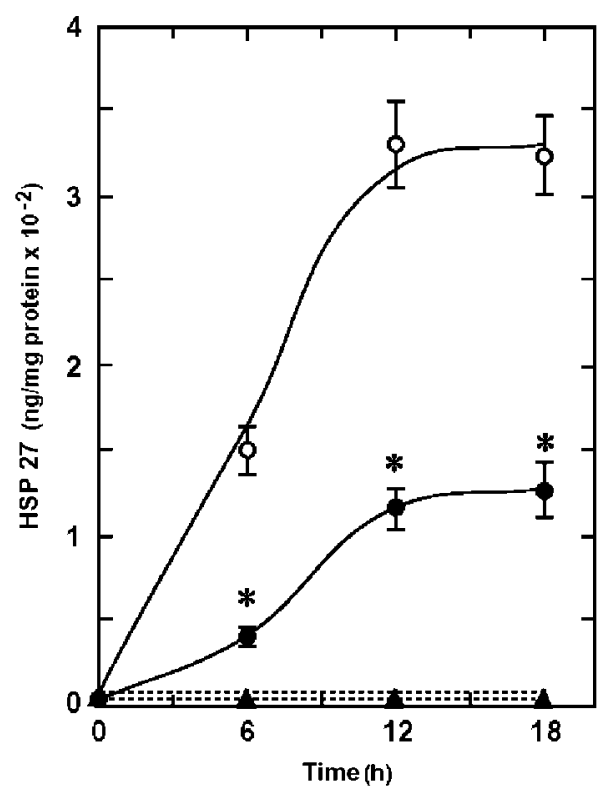

Figure 1 Effect of SP600125 on ET-1-stimulated accumulation of HSP27 in MC3T3-E1 cells. Cultured cells were pretreated with $3 \mu \mathrm{mol} / / \mathrm{l}$ of SP600125 (solid symbols) or vehicle (open symbols) for $60 \mathrm{~min}$, and then stimulated by $3 \mathrm{nmol} / \mathrm{I} \mathrm{ET}-1$ (circles) or vehicle (triangles) for the indicated periods. Each value represents the mean \pm S.E.M. of triplicate determinations. Similar results were obtained with two additional and different cell preparations. ${ }^{\star} P<0.05$ compared with the value of ET-1 alone. 


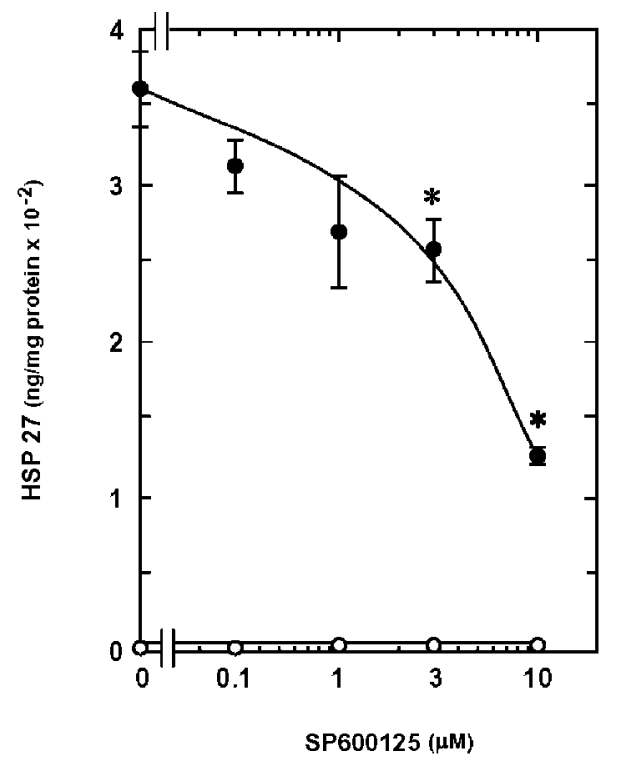

Figure 2 Dose-dependent effect of SP600125 on ET-1-stimulated accumulation of HSP27 in MC3T3-E1 cells. Cultured cells were pretreated with various doses of SP600125 for $60 \mathrm{~min}$, and then stimulated by $3 \mathrm{nmol} / \mathrm{ET}-1$ (solid symbols) or vehicle (open symbols) for $12 \mathrm{~h}$. The accumulation of HSP27 was determined with an enzyme immunoassay. Each value represents the mean \pm S.E.M. of triplicate determinations. Similar results were obtained with two additional and different cell preparations. ${ }^{\star} P<0.05$ compared with the value of ET-1 alone.

SP600125 by itself had little effect on the level of HSP27 mRNA, but markedly reduced the ET-1increased level of HSP27 mRNA (Fig. 4).

\section{Effects of calphostin C and Go 6976 on ET-1-stimulated phosphorylation of SAPK/JNK in MC3T3-E1 cells}

We have previously shown that ET-1 activates protein kinase C via phosphoinositide-hydrolyzing PLC and phosphatidylcholine-hydrolyzing PLD in osteoblastlike MC3T3-E1 cells (12). In order to investigate

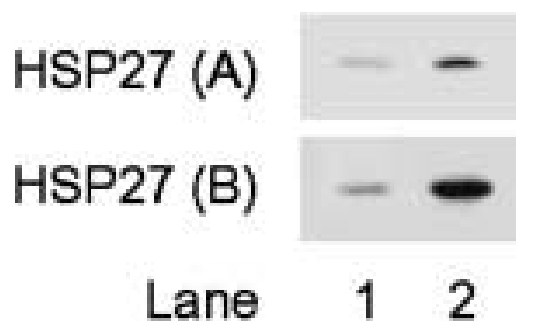

Figure 3 ET-1-increased levels of HSP27 in MC3T3-E1 cells. Cultured cells were stimulated by $0.1 \mu \mathrm{mol} / \mathrm{I} \mathrm{ET}-1$ or vehicle for $12 \mathrm{~h}$. The extracts of cells that contained $40 \mu \mathrm{g}$ protein were subjected to SDS-PAGE with subsequent Western blotting analysis with two different antibodies for HSP27: (A) the antibodies used in the enzyme immunoassay and $(B)$ the antibodies obtained from a commercial source. Lane 1, unstimulated cells.

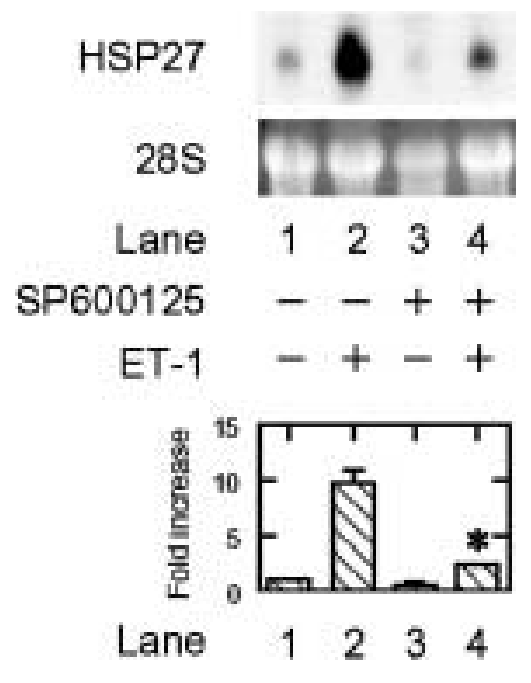

Figure 4 Effect of SP600125 on ET-1-increased HSP27 mRNA level in MC3T3-E1 cells. Cultured cells were pretreated with $10 \mu \mathrm{mol} / \mathrm{I} \mathrm{SP} 600125$ or vehicle for $60 \mathrm{~min}$, and then stimulated by $3 \mathrm{nmol} / \mathrm{I} \mathrm{ET}-1$ or vehicle for $2 \mathrm{~h}$. Cells were harvested and total RNA was isolated. RNA $(20 \mu \mathrm{g})$ from each sample was subjected to electrophoresis and blotted onto a nitrocellulose membrane. The membrane was then allowed to hybridize with cDNA probe for HSP27. Bands of 28S rRNA are shown for reference. The histogram shows quantitative representations of ET-1-induced HSP27 mRNA levels obtained from laser densitometric analysis after normalization to the levels of $28 \mathrm{~S}$ rRNA of three independent experiments. Each value represents the mean \pm S.E.M. of triplicate determinations. Similar results were obtained with two additional and different cell preparations. ${ }^{\star} P<0.05$ compared with the value of ET-1 alone.

whether SAPK/JNK acts at a point downstream of the protein kinase $\mathrm{C}$ in the ET-1-stimulated HSP27 induction in MC3T3-E1 cells, we examined the effect of calphostin C, an inhibitor of protein kinase C (22), on the ET-1-induced phosphorylation of SAPK/JNK. Calphostin C significantly attenuated the SAPK/JNK phosphorylation induced by ET-1 (Fig. 5A). Densitometric analysis showed that calphostin C caused a $43 \%$ reduction in the ET-1 effect. In addition, the ET-1induced phosphorylation of SAPK/JNK was suppressed by Go 6976, another inhibitor of protein kinase C (23) (Fig. 5B). Densitometric analysis then showed that Go 6976 elicited a $40 \%$ reduction in the ET-1 effect.

\section{Effect of SP600125 on TPA-induced phosphorylation of SAPK/JNK in MC3T3-E1 cells}

We further examined the effect of SP600125 on the SAPK/JNK phosphorylation induced by TPA, a protein kinase C-activating phorbol ester (24). TPA alone time-dependently stimulated the phosphorylation of SAPK/JNK (data not shown). SP600125 markedly suppressed the TPA-induced phosphorylation of SAPK/JNK (Fig. 6). Densitometric analysis showed that SP600125 elicited a $70 \%$ reduction in the TPA effect. 

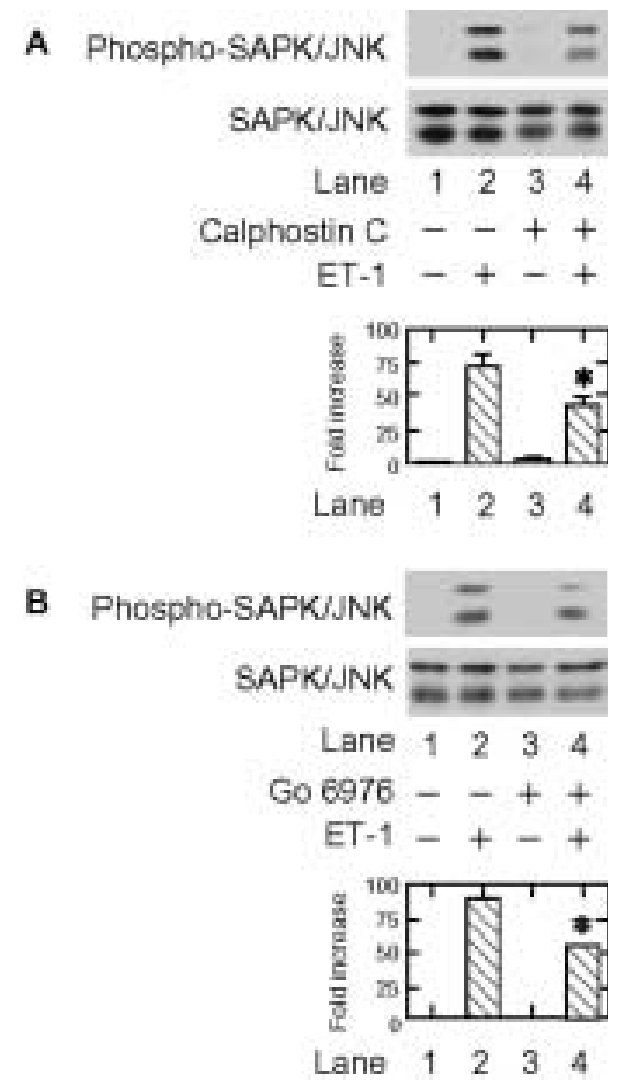

Figure 5 Effects of calphostin C and Go 6976 on ET-1induced phosphorylation of SAPK/JNK in MC3T3-E1 cells. Cultured cells were pretreated with $3 \mu \mathrm{mol} / \mathrm{l}$ calphostin $\mathrm{C}(\mathrm{A})$, Go 6976 (B) or vehicle for $60 \mathrm{~min}$, and then stimulated by $0.1 \mu \mathrm{mol} / / \mathrm{ET}-1$ or vehicle for $30 \mathrm{~min}$. The extracts of cells were subjected to SDS-PAGE with subsequent Western blotting analysis with antibodies against phospho-specific SAPK/JNK or SAPK/JNK. The histogram shows quantitative representations of the levels of ET-1-induced phosphorylation obtained from laser densitometric analysis after normalization to the levels of SAPK/JNK of three independent experiments. Each value represents the mean \pm S.E.M. of triplicate determinations. Similar results were obtained with two additional and different cell preparations. ${ }^{*} P<0.05$ compared with the value of ET-1 alone.

\section{Combination effect of SP600125 and p38 MAP kinase inhibitor on accumulation of HSP27 stimulated by ET-1 in MC3T3-E1 cells}

We have previously shown that SB203580, a specific inhibitor of p38 MAP kinase (25), significantly suppressed ET-1-induced accumulation of HSP27 and the mRNA levels for HSP27 (14). We therefore examined the combination effect of SP600125 and SB203580 on ET-1-stimulated HSP27 accumulation. SP600125 and SB203580 additively suppressed accumulation of HSP27 by ET-1 (Fig. 7). In addition, the ET-1-stimulated accumulation of HSP27 was reduced additively by SP600125 and PD169316, another inhibitor of p38 MAP kinase (26) (Fig. 7).

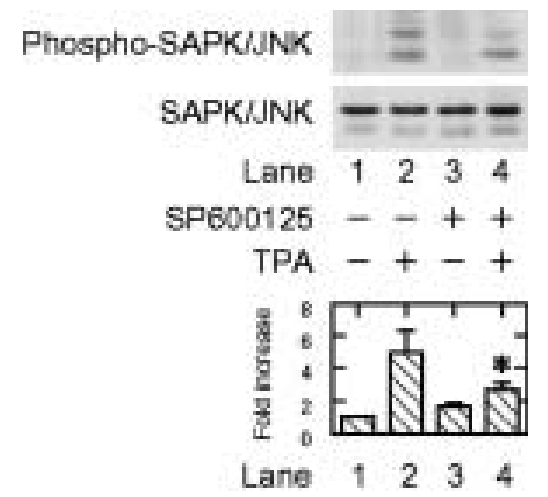

Figure 6 Effect of SP600125 on TPA-induced phosphorylation of SAPK/JNK in MC3T3-E1 cells. Cultured cells were pretreated with $3 \mu \mathrm{mol} / \mathrm{I} \mathrm{SP} 600125$ or vehicle for $60 \mathrm{~min}$, and then stimulated by $0.1 \mu \mathrm{mol} / / \mathrm{TPA}$ or vehicle for $30 \mathrm{~min}$. The extracts of cells were subjected to SDS-PAGE with subsequent Western blotting analysis with antibodies against phospho-specific SAPK/JNK or SAPK/JNK. The histogram shows quantitative representations of the levels of ET-1-induced phosphorylation obtained from laser densitometric analysis after normalization to the levels of SAPK/JNK of three independent experiments. Each value represents the mean \pm S.E.M. of triplicate determinations. Similar results were obtained with two additional and different cell preparations. ${ }^{*} P<0.05$ compared with the value of ET-1 alone.

\section{Discussion}

It is well known that the MAP kinase superfamily mediates intracellular signaling of various agonists and plays crucial roles in cellular functions including proliferation, differentiation, and cell death in a variety of cells (27). Three major MAP kinases, p44/p42 MAP kinase, p38 MAP kinase, and SAPK/JNK, are recognized to transduce signals in mammalian cells (27). We earlier reported that ET-1 activates p44/p42 MAP kinase and p38 MAP kinase in osteoblast-like MC3T3-E1 cells and that p38 MAP kinase, but not p44/p42 MAP kinase, plays a role in ET-1-stimulated HSP27 induction $(13,14)$. We have recently demonstrated that ET-1 activates SAPK/JNK in addition to p44/p42 MAP kinase and p38 MAP kinase in MC3T3-E1 cells (15). We therefore conducted the present study to investigate whether SAPK/JNK plays a role in ET-1-stimulated HSP27 induction in these cells.

In the present study, we showed that SP600125 significantly reduced the ET-1-induced accumulation of HSP27 in MC3T3-E1 cells. We have already found that SP600125 truly reduces the phosphorylation of SAPK/JNK induced by ET-1 in these cells. In addition, the ET-1-increased level of HSP27 mRNA was suppressed by SP600125. Our findings therefore suggest that $\mathrm{SAPK} / \mathrm{JNK}$ is involved in the ET-1-induced HSP27 as well as p38 MAP kinase in osteoblast-like MC3T3-E1 cells. It is recognized that HSP27 phosphorylation is catalyzed by the MAP kinases such as p38 MAP kinase (1). We previously reported that the phosphorylation of p38 MAP kinase induced by ET-1 occurs within $10 \mathrm{~min}$ and returns to the basal level 


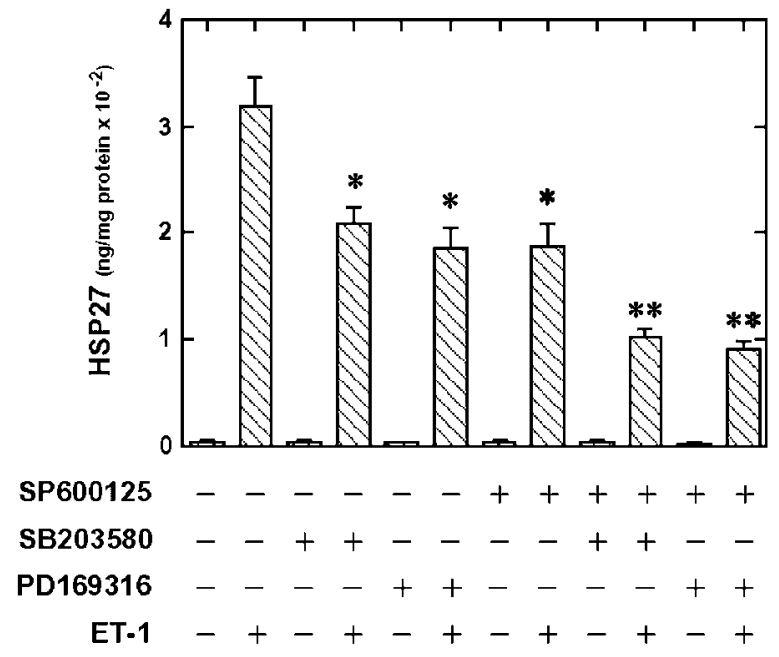

Figure 7 Combination effect of SP600125 and p38 MAP kinase inhibitor on accumulation of HSP27 stimulated by ET-1 in MC3T3$\mathrm{E} 1$ cells. Cultured cells were pretreated with $3 \mu \mathrm{M}$ SB203580, $10 \mu \mathrm{M}$ PD169316 or vehicle for $60 \mathrm{~min}$ in the presence or absence of $3 \mu \mathrm{M}$ SP600125, and then stimulated by $3 \mathrm{nM} \mathrm{ET}-1$ or vehicle for $12 \mathrm{~h}$. Each value represents the mean \pm S.E.M. of triplicate determinations. Similar results were obtained with two additional and different cell preparations. ${ }^{*} P<0.05$ compared with the value of ET-1 alone. ${ }^{* *} P<0.05$ compared with the value of ET-1 pretreated with SB203580, PD169316, or SP600125.

until 60 min after the ET-1 stimulation, suggesting that the ET-1-activated p38 MAP kinase affects their substrates within $1 \mathrm{~h}$ (14). On the other hand, the levels of HSP27 in unstimulated MC3T3-E1 cells were quite low ( $<1 \mathrm{ng} / \mathrm{mg}$.protein) (14). In addition, we have shown that the ET-1-increased accumulation of HSP2 7 became significant at $4 \mathrm{~h}$ after the stimulation (14). It therefore seems unlikely that ET-1-activated p38 MAP kinase phosphorylates HSP27 in osteoblastlike MC3T3-E1 cells.

We have previously reported that ET-1 stimulates both phosphoinositide-hydrolyzing PLC and phosphatidylcholine-hydrolyzing PLD, resulting in the activation of the protein kinase $\mathrm{C}$ in osteoblast-like MC3T3-E1 cells (12). In the present study, TPA, a direct activator of protein kinase C (24), truly phosphorylated SAPK/JNK and SP600125 inhibited the phosphorylation. It is well recognized that MAP kinases are activated by phosphorylation of threonine and tyrosine residues by dual-specificity MAP kinase kinase (27, 28). These data thus suggest that SAPK/JNK functions at a point downstream of the protein kinase $\mathrm{C}$ in MC3T3-E1 cells. Furthermore, we have demonstrated that the ET-1-induced phosphorylation of SAPK/JNK was attenuated by calphostin C (22) and Go 6976 (23). Based on our findings, it is most likely that ET-1 activates SAPK/JNK via the protein kinase $\mathrm{C}$, which plays a part in the induction of HSP27 in the osteoblast-like MC3T3-E1 cells. However, the inhibitory effect of SP600125 on the ET-1-induced accumulation of HSP27 and mRNA levels for HSP27 was partial. In a previous study (14), we demonstrated that activation of p38 MAP kinase is involved in the ET-1-induced HSP27 in MC3T3-E1 cells, but the inhibitory effect of SB203580, a specific inhibitor of p38 MAP kinase (25), was partial. In the present investigation, we have shown that SP600125 and a p38 MAP kinase inhibitor additively suppresses the accumulation of HSP27 by ET-1. SP600125 hardly affected the ET-1induced phosphorylation of p38 MAP kinase, and SB203580 had reportedly little effect on the ET-1induced SAPK/JNK phosphorylation in MC3T3-E1 cells (15). Taking our results as a whole into account, it is most likely that HSP27 induction stimulated by ET-1 is mediated through activation of both p38 MAP kinase and SAPK/JNK in the osteoblast-like MC3T3E1 cells. It is well known that low molecular weight HSPs, such as HSP27, as well as high molecular weight HSPs, such as HSP90 and HSP70, act as molecular chaperones in protein folding, oligomerization and translocation (1). It is likely that ET-1-stimulated accumulation of HSP 27 plays a role in the regulation of osteoblast cell functions, such as secretion, proliferation, or differentiation. To co-ordinate the functions in the osteoblast, SAPK/JNK and p38 MAP kinase seem to regulate the induction of HSP 27 co-operatively. It has been reported that HSP 27 shows a protective effect against apoptosis in neuronal cells (29). In addition, the up-regulation of HSP 27 by ET-1 seems to play a role in the cell survival pathways, resulting in an increase of resistance to apoptosis. Taking these into account, it is most likely that ET-1-induced HSP 27 through the activation of SAPK/JNK in addition to p38 MAP kinase, finely co-ordinates the ET-1-provocated cellular events to minimize the damage in osteobasts. Further investigations are required to clarify the exact roles of HSP27 in osteoblasts.

In conclusion, our present results strongly suggest that ET-1-activated SAPK/JNK, in addition to p38 MAP kinase, plays a part in ET-1-induced HSP27 in osteoblasts.

\section{Acknowledgements}

This investigation was supported in part by a Grant-inAid for Scientific Research from the Ministry of Education, Science, Sports and Culture of Japan. We are grateful to Y Okamoto for skilful secretarial assistance.

\section{References}

1 Benjamin IJ \& McMillan DR. Stress (heat shock) proteins: molecular chaperones in cardiovascular biology and diseases. Circulation Research 199883 117-132.

2 Nijweide PJ, Burger EH \& Feye JH. Cells of bone: proliferation, differentiation, and hormonal regulation. Physiological Reviews $198666855-886$.

3 Yasuda H, Shima N, Nakagawa N, Yamaguchi K, Kinosaki M, Mochizuki S et al. Osteoclast differentiation factor is a ligand for 
osteoprotegerin/osteoclastgenesis-inhibitory factor and is identical to TRANCE/RANKL. PNAS 199895 3597-3602.

4 Shakoori AR, Oberdorf AM, Owen TA, Weber LA, Hickey E, Stein JL et al. Expression of heat shock genes during differentiation of mammalian osteoblasts and promyelocytic leukemia cells. Journal of Cellular Biochemistry $1992 \mathbf{4 8} 277-287$.

5 Cooper LF \& Uoshima K. Differential estrogenic regulation of small M(r) heat shock protein expression in osteoblasts. Journal of Biological Chemistry 1994269 7869-7873.

6 Tokuda H, Kozawa O, Niwa M, Matsuno H, Kato K \& Uematsu T. Mechanism of prostaglandin $\mathrm{E}_{2}$-stimulated heat shock protein 27 induction in osteoblast-like MC3T3-E1 cells. Journal of Endocrinology $2002172271-281$.

7 Hatakeyama D, Kozawa O, Niwa M, Matsuno H, Ito H, Kato K et al. Upregulation by retinoic acid of transforming growth factor- $\beta$ stimulated heat shock protein 27 induction in osteoblasts: involvement of mitogen-activated protein kinases. Biochimica et Biophysica Acta 20021589 15-30.

8 Masaki T. Endothelins: homeostatic and compensatory actions in the circulatory and endocrine systems. Endocrine Reviews 1993 $14256-268$.

9 Pollock DM, Keith TL \& Highsmith RF. Endothelin receptors and calcium signaling. FASEB Journal 19959 1196-1204.

10 Erlebacher A, Filvaroff EH, Girelman SE \& Derynck R. Toward a molecular understanding of skeletal development. Cell $1995 \mathbf{8 0}$ $371-378$.

11 Stern PH, Tatrai A, Semler DE, Lee SK, Lakatos P, Strieleman PJ et al. Endothelin receptors, second messengers, and actions in bone. Journal of Nutrition 199525 2028S-2032S.

12 Suzuki A, Oiso Y \& Kozawa O. Effect of endothelin-1 on phospholipase D activity in osteoblast-like cells. Molecular and Cellular Endocrinology 19945 193-196.

13 Kawamura H, Otsuka T, Tokuda H, Matsuno H, Niwa M, Matsui N et al. Involvement of $\mathrm{p} 42 / \mathrm{p} 44$ MAP kinase in endothelin-1induced interleukin- 6 synthesis in osteoblast-like cells. Bone $199924315-320$.

14 Kawamura H, Otsuka T, Matsuno H, Niwa M, Matsui N, Kato K et al. Endothelin-1 stimulates heat shock protein 27 induction in osteoblasts: involvement of p38 MAP kinase. American Journal of Physiology 1999277 E1046-E1054.

15 Wang X, Tokuda H, Hirade K \& Kozawa O. Stress-activated protein kinase/c-Jun N-terminal kinase (JNK) plays a part in endothelin-1induced vascular endothelial growth factor synthesis in osteoblasts. Journal of Cellular Biochemistry 200287 417-423.

16 Sudo H, Kodama H, Amagai Y, Yamamoto S \& Kasai S. In vivo differentiation and calcification in a new clonal osteogenic cell line derived from newborn mouse calvaria. Journal of Cell Biology $198396191-198$.

17 Kozawa O, Tokuda H, Miwa M, Kotoyori J \& Oiso Y. Cross-talk regulation between cyclic AMP production and phosphoinositide hydrolysis induced by prostaglandin $\mathrm{E}_{2}$ in osteoblast-like cells. Experimental Cell Research 1992198 130-134.

18 Inaguma Y, Goto S, Shinohara H, Ohshima K \& Kato K. Physiological and pathological changes in levels of the two small stress proteins, HSP27 and $\alpha \mathrm{B}$ crystallin in rat hindlimb muscles. Journal of Biochemistry $199314378-384$.

19 Kato K, Ito H, Hasegawa K, Inaguma Y, Kozawa O \& Asano T. Modulation of the stress-induced synthesis of hsp27 and $\alpha \mathrm{B}$-crystallin by cyclic AMP in $\mathrm{C} 6$ rat glioma cells. Journal of Neurochemistry $199666946-950$.

20 Laemmli UK. Cleavage of structural proteins during the assembly of the head of bacteriophage T4. Nature 1970 227 680-685.

21 Bennett BL, Sasaki DT, Murray BW, O'Leary EC, Sakata ST, Xu W et al. SP600125, an anthrapyrazolone inhibitor of Jun N-terminal Kinase. PNAS 200198 13681-13686.

22 Kobayashi E, Nakano H, Morimoto M, Tamaoki T \& Calphostin C. (UCN-1028C), a novel microbial compound, is a highly potent and specific inhibitor of protein kinase C. Biochemical and Biophysical Research Communications 1989159 548-553.

23 Martiny-Baron G, Kazanietz MG, Mischak H, Blumberg PM, Kochs G, Hug $\mathrm{H}$ et al. Selective inhibition of protein kinase $\mathrm{C}$ isozymes by the indolocarbazole Go 6976. Journal of Biological Chemistry $19932689194-9197$.

24 Nishizuka Y. Studies and perspectives of protein kinase C. Science 1986233 305-312.

25 Cuenda A, Rouse J, Doza YN, Meier R, Cohen P, Gallagher TF et al. SB203580 is a specific inhibitor of a MAP kinase homologue which is stimulated by cellular stresses and interleukin-1. FEBS. Letters $1995 \mathbf{3 6 4} 229-233$.

26 Kummer JL, Rao PK \& Heidenreich KA. Apoptosis induced by withdrawal of trophic factor is mediated by p38 mitogen-activated protein kinase. Journal of Biological Chemistry 1997227 20490-20494.

27 Widmann C, Gibson S, Jarpe MB \& Johnson GL. Mitogen-activated protein kinase: conservation of a three-kinase module from yeast to human. Physiological Reviews 199979 143-180.

28 Raingeaud J, Gupta S, Rogers JS, Dickens M, Han J, Ulevitch RJ et al. Pro-inflammatory cytokines and environmental stress cause p38 MAP kinase activation by dual phosphorylation on tyrosine and threonine. Journal of Biological Chemistry 1995 270 7420-7426.

29 Wagstaff MJD, Collaço-Moraes Y, Smith J, de Belleroche JS, Coffin RS \& Latchman DS. Protection of neuronal cells from apoptosis by Hsp 27 delivered with a herpes simplex virus-based vector. Journal of Biological Chemistry 1999 274 5061-5069.

Received 25 February 2003

Accepted 3 June 2003 